Abstract

\title{
Physico-chemical Properties of Silicea terra 200cH and Activity on Macrophages in vitro
}

\author{
Sandra AG Pinto*, Michelle Sanchez Aguiar, Elizabeth C P Hurtado, Leoni V Bonamin
}

Universidade Paulista, São Paulo, Brazil

* sandraagp@hotmail.com - https://orcid.org/0000-0002-4380-8312

Introduction Silicea terra $200 \mathrm{cH}$ can modulate macrophage activity in mice inducing resolution of chronic wounds, whose mechanisms are unknown. Herein, we describe the relation between the activity of Silicea terra 200cH in vitro, on macrophages infected with Calmette-Guérin Bacilli (BCG) a microorganism involved in chronic granuloma lesions - and physico-chemical properties of the remedy. Objective Establish the relation between physico-chemical properties and biological activity of Silicea terra 200cH in vitro. Methods BCG-infected RAW 264.7 macrophages were analyzed considering their capacity of bacilli internalization, lysosome activity, hydrogen peroxide $\left(\mathrm{H}_{2} \mathrm{O}_{2}\right)$ and cytokines production, using a CBA (BD) kit. The vehicle (succussed water) was used as control. The electrical conductivity and the presence of micro particles in the remedy were also studied. Results Silicea terra 200cH showed significant reduction of hydrogen peroxide production $(\mathrm{p} \leq 0.001)$, higher lysosome activity $(\mathrm{p} \leq 0.001)$ and increase of IL-10 production $(\mathrm{p} \leq 0.05)$, an antiinflammatory cytokine, in relation to the control. The electrical conductivity of Silicea terra $200 \mathrm{cH}$ was statistically higher in relation to pure water $(\mathrm{p}<0.001)$ but not in relation to succussed water (vehicle), micro in clusters only in Silicea terra $200 \mathrm{cH}$, but not in the control. Discussion The biological effects show higher digestive activity of the macrophages, with higher expression of IL-10, an anti-inflammatory cytokine, reduction in the production of hydrogen peroxide and, therefore, lower potential for oxidative stress and tissue damage. Such outcomes explain the clinical use of Silicea terra. The changes in electric conductivity were related with the succusion itself and are compatible with the electrical field hypothesis for homeopathy. The changes in the topography of the particles, exclusive in Silicea terra $200 \mathrm{cH}$, suggest the existence of cause-effect relation with the biological activity, at least partially. Further studies are still necessary to establish the detailed mechanisms of action.

Keywords: macrophages, Silicea terra, electric conductivity, micro particles.

Financial support: UNIP

(C) International Journal of High Dilution Research.

Not for commercial purposes. 